Даниела Г. Драган, «Трансграничная политика Румынии на примере «еврорегионов»

\title{
Трансграничная политика Румынии на примере «еврорегионов»
}

\author{
Даниела Г. Драган \\ Дипломатическая академия МИД России, Москва, Россия, \\ dragandana90@yahoo.com
}

\begin{abstract}
Аннотация: на примере еврорегионального сотрудничества в статье делается попытка уточнения основных направлений трансграничной политики Румынии. Автором прослежена эволюция значения «границ», а также представлены базовые научные подходы в изучении. В статье дан обзор «еврорегионов» с участием Румынии. Выявлено, что в их институализации преобладало два этапа (в 1997 г. и в 2002 г.). Сам процесс тесно связан с установлением договорно-правовой базы межгосударственного сотрудничества. Одновременно он связан и с тенденциями внутриполитического и внешнеполитического курса Румынии и приграничных стран. Субрегиональное сотрудничество развивалось под воздействием таких факторов как построение рыночной экономики и демократии, интеграция в Западные организации. При этом негативное влияние на трансграничную политику оказывал комплекс межгосударственных проблем. На современном этапе Румыния установила со всеми приграничными странами формат еврорегионального взаимодействия. При этом их анализ позволил автору проследить особенности реализации трансграничной политики страны.
\end{abstract}

Ключевые слова: трансграничное сотрудничество, еврорегион, Румыния, граница

Для цитирования: Драган Д. Г. Трансграничная политика Румынии на примере «еврорегионов». Проблемы постсоветского пространства. 2020;7(2):227-236. DOI: https://doi.org/10.24975/2313-8920-2020-7-2-227-236 
$20207(2): 227-236$

Проблемы постсоветского пространства / Post-Soviet Issues

Romania's Cross-border Policy towards Euroregions

\author{
Daniela G. Dragan \\ Diplomatic Academy of the Ministry of Foreign Affairs of Russia, Moscow, Russia, \\ dragan dana90@yahoo.com
}

\begin{abstract}
The article highlights the main directions of Romania's cross-border policy in view of euroregional cooperation. The author traces the evolution of the term "border" as well as describes the basic scientific approaches to its studies. The article provides an overview of the "Euroregion" which includes Romania. It has become apparent that its institutionalization was a two-stage process (in 1997 and 2002). The process itself is closely connected with the establishment of legal framework for interstate cooperation. At the same time it is dependent on the foreign and domestic policy trends of both Romania and its neighbors. Sub-regional cooperation has evolved under the influence of such factors as the establishment of market economy and democracy, integration into Western organizations. At the same time a whole complex of interstate problems has had a negative impact on cross-border policy. Currently Romania maintains relations with all neighboring countries in the format of euroregional cooperation. Its analysis has enabled the author to outline the special characteristics of the implementation of the country's cross-border policy.
\end{abstract}

Keywords: cross-border cooperation, euroregion, Romania, border

For citation: Dragan D. G. Romania's Cross-border Policy towards Euroregions. Post-Soviet Issues. 2020;7(2):227-236. DOI: https://doi.org/10.24975/2313-8920-2020-7-2-227-236

Received 21.03.2020

Revised 19.04.2020

Published 25.05.2020

\section{ВВЕДЕНИЕ}

В 2017 г. Академией наук Румынии был завершен проект «Стратегия развития Румынии на 20-летний период» с публикацией итоговых работ. Проект был реализован в несколько этапов. В рамках первого этапа (2014 г.) были определены тематики одиннадцати направлений, сформированы рабочие группы и координаторы. На втором этапе (2015 г.) отмечен публикацией первого выпуска Стратегии. В нем представлен анализ текущего положения областей исследования, swot анализ, а также отражены объективы и ожидаемые результаты. Последующий, третий, этап разработки
Стратегии (2016 г.) имел цель определить приоритеты на горизонт планирования: краткосрочный (3-5 лет), среднесрочный (10 лет) и долгосрочный (20 лет). Анализ был опубликован во втором выпуске Стратегии. На четвертом этапе публикуется третий выпуск. В работе предлагались сценарии развития (пессимистический, реалистический и оптимистический). В рамках пятого этапа (2017 г.) было реализовано краткое изложение Стратегии и исполнительного резюме, соответствующие публикации стали завершающими. Таким образом, Стратегия 
Даниела Г. Драган,

«Трансграничная политика Румынии на примере «еврорегионов»

\section{Проблемы постсоветского пространства / Post-Soviet Issues}

$20207(2): 227-236$

представлена пятью выпусками, которые суммарно составляют свыше 3000 страниц.

В исследовании были включены все области жизнедеятельности государства, в том числе и внешняя политика (Глава 11. Румыния в эпоху глобализации - пространство и традиции пересечения цивилизаций, баланса и умеренности).

Академическое видение развития страны важно для понимания концептуальных основ, формирующих румынскую стратегическую мысль. Внимание привлекло определение научным сообществом внешних географических границ, которые для Румынии представляют «жизненное пространство» используя терминологию Ф. Ратцела. В соответствии со Стратегией ими являются территории, формирующиеся в радиусе 1500-2000 км, к которым относят Балканы (Западные и Восточные), страны, состоящие в Восточном соседстве $\mathrm{EC}$, Кавказ, страны Каспийского региона и т. д. [1]. Таким образом, анализ трансграничной политики Румынии на этом фоне представляет интерес с точки зрения понимания комплекса проблем, а также возможностей в реализации стратегических целей внешней политики страны.

\section{ГРАНИЦЫ КАК ОБЪЕКТ ИССЛЕДОВАНИЯ}

Истоки исследования «границ» в современном политическом дискурсе переводят к использованию категории, представляющей собой, линию раздела территорий государств, которые являются суверенными и международно признанными. Между тем, современный предмет их исследования более обширен.

Преобладает несколько подходов в изучении границ, которые можно разделить на традиционные и постмодернистские. Их деление условное, так как новые подходы применяются синхронно вместе со старыми. Традиционный подход связан с выде- лением государственных границ на основе делимитации и демаркации. Как справедливо отметил отечественный эксперт лимологии Колосов В. А., «история человечества - это история войн, а большинство войн ставило конечной целью изменение границ» [2]. Подтверждением тому является и цикл глобальных военных конфликтов вначале XX в., посредством которых вновь и вновь происходило перекраивание границ государств. Как следствие они стали восприниматься, как передовая оборонительная линия, нерушимая и непроницаемая преграда для любых враждебных проникновений [3]. Исходя из этого, в исследованиях доминировало представление о том, что политическое разграничение пространства на всех уровнях - это средство удовлетворения двух базовых потребностей общества: обеспечение безопасности (защиты от внешних и внутренних угроз) и выделение территории, контролируемой определенной политической, культурной и социальной группой, обладающей выраженной идентичностью [3].

Геополитическая мысль о границах основывалась на трудах Ф. Ратцела. Им вводилось в оборот понятие «жизненного пространства», рассматривая «государство как живой организм, которому требуется определенное пространство для развития» [4]. Границы, таким образом, рассматривались как изменчивые и динамичные элементы.

Французская геополитическая школа, наоборот, отрицала географический детерминизм Ф. Ратцела, обосновывая примат воли и инициативы человека. В. Де ла Бланш выдвинул принципиально важный для современной геополитики принцип «поссибилизма», согласно которому то или иное пространство только предоставляет государству возможности его геополитической конфигурации, но реализация этих возможностей зависит от воли людей [5]. 
$20207(2): 227-236$

Проблемы постсоветского пространства / Post-Soviet Issues

Новый импульс в изучении границ был вызван развитием интеграционных процессов в Западном мире в середине XX в., отразившимся на изменении содержания и понимания границ. В центре внимания исследователей были факторы, направленные на объяснение их функции. Таким образом, функциональным подходом удалось выявить их значение в качестве барьерной, контактной и фильтрующей зоны. В политологии функциональный подход применен в неолиберальной теории и связан, прежде всего с именами Д. Митрани, Я. Тинбергена, Э. Хааса и Л. Линдберга. Именно функционалисты, рассматривая процесс распространения властного влияния одного обладающего юрисдикцией центра на конкретную территорию через делегирование полномочий, сформулировали так называемую концепцию переливания (spillover) [6]. Иными словами происходит децентрализация, когда государство передает часть своих функций с центра на приграничные местные и региональные власти в интересах общей выгоды и пользы. Это принцип, лежавший в основе трансграничной политики.

Постмодернистские подходы сопряжены с теорией мировых систем и территориальных идентичностей. Продолжая теорию функционалистов, развивается идея, согласно которой рост трансграничных потоков и влияния трансграничных субъектов, приводит к утрате границами части барьерных функций. Тем самым, ни одна страна ныне не может быть абсолютно изолирована от соседей. Даже если двусторонние отношения очень холодны, соседние страны обычно заинтересованы в транзите, развитии коммуникаций, совместном использовании природных ресурсов и международных речных бассейнов, предупреждении неблагоприятных и опасных природных и техногенных явлений и т. п. [3].
Затем теория территориальных идентичностей, развивает идею, согласно которой значения границ формируются на базе общественного сознания и самоидентификации человека с определенной территорией. С одной стороны, значительные по численности этнические, культурные и региональные группы могут не разделять официально провозглашаемые ценности, представления о происхождении государства, его исторической миссии, границах и месте в мире, «естественных» врагах и угрозах национальной безопасности и т. д. Это создает предпосылки для неустойчивости границ и стабильности государства. С другой стороны, в условиях всемирной интеграции и унификации меняется сам этнический состав населения и его идентичность. Демографическая ситуация тем самым преобразовывает границу из «линии раздела» в «контактную зону». В этой связи обеспечение национальной безопасности трансформируется, так как оно затрагивает экономическую, политическую и культурную область и не может быть реализовано только военным путем. Что касается границ, то в современных условиях они явно становятся все более дифференцированными. В итоге сама система границ эволюционирует от единственных рубежных линий — к множеству, от линий — к зонам, от физических границ - к культурным, от непроницаемых барьеров - к линиям взаимодействия [3].

\section{«ЕВРОРЕГИОНЫ»}

Определение «еврорегион» имеет несколько трактовок. Базовой является форма трансграничного сотрудничества, образующегося между двумя или несколькими административно-территориальными единицами, расположенными в приграничных районах соседствующих государств. 
Даниела Г. Драган,

«Трансграничная политика Румынии на примере «еврорегионов»

\section{Проблемы постсоветского пространства / Post-Soviet Issues}

$20207(2): 227-236$

Вначале 1990 гг. Румыния сдержанно относилась к формированию трансграничных отношений. Основной причиной являлась неурегулированность вопросов делимитаций и демаркаций границ с приграничными странами. После установления договорно-правовой базы сотрудничества Румыния стала активнее развивать форматы трансграничного взаимодействия. Мощный импульс к развитию «еврорегионов» дал и взятый Бухарестом внешнеполитический курс на интеграцию в ЕС и НАТО.

На современном этапе с участием Румынии функционируют двенадцать «еврорегионов». Среди декларируемых целей их создания: преобразование границ «от разделительной линии в место для диалога»; преодоление взаимного недоверия; укрепление демократии и развитие административных структур; преодоление периферийной позиции и государственной маргинализации; стимулирование экономического роста и развития, улучшение стандартов жизни населения; и достижение европейской интеграции, соответственно.

В 1993 г. был создан первый «еврорегион» - Карпатский. В его состав входили территориально-административные единицы Польши, Венгрии, Словакии, Украины и Румынии. Из-за характера румынского национального законодательства первоначально участвующие уезды обладали статусом наблюдателей, и только в 1997 г., после его реформирования они получили статус членов. К тому времени между Румынией и Венгрией в 1996 г. и Румынией и Украиной в 1997 г. были подписаны Договоры о дружбе и сотрудничестве.

В 1997 г. был реализован «еврорегион ДКМТ» между Румынией, Венгрией и Сербией. В 1998 г. создается «еврорегион Ниж- ний Дунай», в котором участвовали административные районы Румынии, Украины и Молдовы. Второй «еврорегион» в трехстороннем формате Румыния - Украина Молдова образован в 2000 г. — «Верхний Прут». Его география включала северо-восточные административно-территориальные районы Румынии (Ботошань, Сучава), Черновицкая область Украины и молдавские северные районы (Единец, Бельцы).

Создание «еврорегионов» с участием Болгарии было реализовано только к 20012002 гг, хотя Договор о дружбе и сотрудничестве между Бухарестом и Софией был подписан еще в 1992 г. В 2001 г. были созданы «еврорегион Южный Дунай» и «еврорегион Джурджу - Руссе». Уже в 2002 г. «еврорегион Дунай - Доброджя», «еврорегион Данубиус» и ассоциация «Дунай 21». Между административно-территориальными районами Румынии, Болгарии и Сербии в 2005 г. был создан «еврорегион Средний Дунай - Железные ворота». При этом межгосударственный Договор о дружбе и сотрудничестве между Румынией и Сербией был подписан в 2006 г., до этого действовал Договор 1996 г., подписанный с Республикой Югославия.

В результате фрагментации «еврорегиона Карпатский» в конце 2002 г. между Румынией и Венгрией формируется «еврорегион Бихор - Хайду-Бихар». Тогда же в 2002 г. был реализован «еврорегион» с участием Румынии и Молдовы - «Сирет - Прут Днестр» [7].

Таким образом, за исключением Республики Молдова Румыния установила договорно-правовую базу сотрудничества со всеми приграничными странами. Впрочем, в конце 2010 г. Румыния под давлением ЕС подписала с Молдавией Договор о режиме государственной границы, сотрудничестве и взаимной помощи в пограничных вопро- 
$20207(2): 227-236$

Проблемы постсоветского пространства / Post-Soviet Issues

сах. Однако, впоследствии Бухарест отказался его ратифицировать ${ }^{1}$.

Основные направления деятельности «еврорегионов» затрагивают такие сферы, как транспорт и коммуникации, пространственное планирование, экология и окружающая среда, занятость, культурные обмены, образование, и здравоохранение. Одновременно наблюдалось, что экономическая эффективность румынского приграничья с Болгарией и Венгрией выше, чем с другими приграничными районами. В то же время «еврорегионы» восточной границы включают территориально-административные районы Молдовы и Украины, где компактно проживает румынская этническая группа.

Между тем, в институализации трансграничного сотрудничества выделяются два основных этапа. Первый в 1997 г., когда еврорегиональное сотрудничество развивалось под воздействием таких схожих для стран факторов, как построения рыночной экономики и демократии, контекст интеграции в ЕС и НАТО и выполнение требований по урегулированию отношении с соседями. Второй этап фиксируется преимущественно в 2002 г. Ключевое место в нем занимала Болгария. Отношения с ней развивались вокруг таких тем, как совместное вступление в ЕС и НАТО и реализация инфраструктурных проектов, в частности строительство мостов через Дунай соединяющих приграничные районы.

\section{ЦЕЛИ ТРАНСГРАНИЧНОЙ ПОЛИТИКИ РУМЫНИИ}

Стремление Румынии к участию и реализации трансграничных отношении обусловлено реализацией нескольких внешнеполитических задач.

Первоначально Закон № 151 от 1998 г. о региональной политике Румынии опреде- ляет (ст. 2) нацеленность на стимулирование трансграничного сотрудничества, в том числе в рамках еврорегионов, «способствующих экономическому и институциональному развитию, реализации проектов, представляющих общий интерес» [8]. В редакции Закона № 315 от 2004 г. (ст.3) [9] цели, лежащие в основе трансграничного сотрудничества Румынии, детализированы. Ими предусмотрено: содействие сотрудничеству между регионами, общинами и властными структурами в решении общих проблем путем разработки и реализации трансграничных стратегий и проектов, которые способствуют экономическому развитию и повышению уровня жизни; содействие в реализации добрососедских отношений, социальной стабильности и экономическому прогрессу в приграничных регионах путем финансирования проектов, приносящих видимые выгоды регионам и общинам в этих регионах; поддержка децентрализации путем продвижения местных инициатив, реализуемых в рамках местных стратегий.

Между тем, как выразился экс-министр иностранных дел Адриан Северин, еврорегионы для Румынии «означали национальное воссоединение без изменения границ» [10]. В этом смысле одна из основных целей приграничного сотрудничества Румынии состояла и в том, что они создавались в том числе, с целью защиты румынского национального меньшинства, проживающего на территории соседних стран. Примерно $90 \%$ территории Республики Молдова включено в трансграничное сотрудничество с участием Румынии. Территориально-административные области Украины, участвующие в еврорегиональном сотрудничестве - Черновцы и северо-запад Одессы, составляют исторические

\footnotetext{
1 в 2013 г. Кишинев ратифицировал Договор.
} 
Даниела Г. Драган,

«Трансграничная политика Румынии на примере «еврорегионов»

\section{Проблемы постсоветского пространства / Post-Soviet Issues}

$20207(2): 227-236$

территории межвоенной «Великой Румынии» - северная Буковина и южная Бессарабия. Преимущественно в отношении них применяется ст. 11 Закона о гражданстве Румынии, [11] дающая право на восстановление румынского гражданства.

Впрочем, зеркально установлено и румыно-венгерское еврорегиональное сотрудничество. Участвующие административно-территориальные уезды Румынии относятся к Трансильванскому региону, жители которого по этническому составу примерно на 70\% состоят из венгров. «Секуйский вопрос» до и после вступления стран в ЕС остался в повестке их политики как вопрос «хрупкий», требующий многосторонности. Если его рассматривать в контексте «национального воссоединения без изменения границ», то очевидно, что это не соответствует интересам Румынии. Длительный период Бухарест минимизировал попытки венгерского меньшинства на восстановление автономии «края», которая у них была с 1952-1968 гг. В контексте времени создания «еврорегионов» в 1997 г., ни одна из стран Центрально-Восточной Европы, в том числе Венгрия и Румыния, не были нацелены на введение ревизионной политики по отношению к соседним странам, в противном случае это негативно оценивалось Западными структурами, куда они стремились вступить. В то же время после подписания межгосударственного Договора о дружбе и сотрудничестве и вступления в НАТО и ЕС конкурирующий характер отношений между Румынией и Венгрией не был преодолен. В интересах сохранения внутриполитической стабильности и поддержания благоприятного имиджа на Западе Бухарест стремился в рамках «еврорегионов» реализовать преимущественно социально-экономическое сотрудничество. Среди актуальных проектов «Дороги без границ» (включен в программу «евро- региона ДКМТ») и информирование граждан и содействие в участии в программе ЕС «Европа для граждан» (включен в программу «еврорегиона Бихор - Хайду-Бихар»).

Трансграничное румыно-болгарское сотрудничество реализовалось преимущественно в сфере развития контактных зон посредством строительства мостов, дорог и реализации приграничного технического обслуживания. Среди реализуемых проектов - ввод в эксплуатацию в 2013 г. моста Калафат-Видин состоящего в части приоритетов программы сотрудничества «еврорегиона Дунай 21». На его строительство ушло 13 лет, а сама эксплуатация стала возможной после оказанного ЕС давления на Болгарию и Румынию по его реализации. Между тем Бухарест не проявлял интереса к проекту. Мост, с позиции Румынии, «обходит страну, и минимально включает еe юго-западные маршруты» [12]. Впрочем, как ни парадоксально, сам характер трансграничного взаимодействия стран обуславливался отсутствием интереса к взаимодействию. Определенную роль в этой связи сыграл «ревностный» стиль румыно-болгарского сотрудничества. Бухарест, как и София, оглядывались друг на друга в период вступления стран в ЕС и НАТО, тенденция сохранившаяся и на современном этапе [13]. Таким образом, трансграничная кооперация практически сводилась к традиционному приграничному сотрудничеству и реализации экономических интересов стран в районах межгосударственных границ.

Из всех приграничных стран трансграничные отношения с Сербией выстраиваются в относительно благоприятном ключе. Совместное еврорегиональное взаимодействие затрагивает вопросы экономического развития участвующих районов по обе стороны границы. В то же время, кооперация стран реализуется в трехстороннем формате с уча- 
$20207(2): 227-236$

Проблемы постсоветского пространства / Post-Soviet Issues

стием административно-территориальных единиц Болгарии либо Венгрии. В этой связи, так или иначе, опечаток румыно-венгерского, румыно-болгарского сотрудничества оказывает влияние и на румыно-сербское трансграничное взаимодействие. При этом модель еврорегионального сотрудничества выступает одновременно как инструмент реализации европейской политики. Проекты, инициированные представителями «еврорегионов», финансируются через структурные фонды ЕС (Европейский фонд регионального развития, Европейский социальный фонд и Фонд сплочения), через различные программы (например, INTERREG). Также для проектов с участием стран-кандидатов и ассоциированных членов ЕС, финансирование реализуется через Программы PHARE-CBC (Приграничное сотрудничество), Инструментом помощи перед вступлением (IPA) или Европейского соседства и партнерства (ENPI).

Румыния в реализации трансграничной политики также нацелена на улучшение имиджа страны в сопредельных странах и налаживание контактов с их политической элитой. Одним из сдерживающим факторов сотрудничества Румынии со странами соседями является негативное восприятие ее политики обусловленное прецедентами межгосударственных разбирательств (Украина), ирредентистски-

\section{ЛИТЕРАТУРА}

1. Strategia de dezvoltare a României în următorii 20 de ani. Sumar executiv/ Coord.: acad.IonelValentin Vlad. București: Editura Academiei Române; 2017. C.87

2. Колосов В. География государственных границ: идеи, достижения, практика. Журнал Известия РАН. Серия Географическая. 2008;5:8. ми настроениями (Молдова), политикой в отношении национальных меньшинств, проживающих на территории Румынии (Венгрия) и пересечением экономических интересов (Болгария). Тем не менее, очевидно, что политическая роль Румынии в регионе значительно выросла после вступления страны в ЕС и НАТО и установлении, стратегических отношений с США.

\section{ЗАКЛЮЧЕНИЕ}

Активизация трансграничной политики Румынии во второй половине 1990-х гг. вначале 2000-х гг. имеет в настоящее время двойственные последствия. С одной стороны, Румыния, устанавливая еврорегиональное сотрудничество со всеми приграничными странами значительно расширила двусторонний диалог, способствовала налаживанию межгосударственных контактов, повысила влияние Бухареста в вопросах защиты румынского этнического меньшинства, проживающего на территории соседних стран. С другой стороны, Румынией не удалось эффективно использовать трансграничное взаимодействие в целях снижения негативного восприятия, как собственной политики в соседних странах, так и наоборот. Таким образом, реализация данных задач сохраняет свою актуальность в повестке внешней политики Румынии.

3. Введение в исследования границ / под ред. С.В. Севастьянова, Ю. Лайне, А.А. Киреева. Владивосток: Дальнаука; 2016. С. 45-127.

4. Классика геополитики. ХІХ век. Ф.Ратцел, А.Мэхэн, П.Чаадаев, Н.Данилевский. Москва: Издательство «АСТ»; 2003.720 с.

5. Цыганков П. Французская школа геополитики в 2000 годах: отношения ЕС с Россией. Международные проиессы. 2011;2(26):5. 
Даниела Г. Драган, «Трансграничная политика Румынии на примере «еврорегионов»

\section{Проблемы постсоветского пространства / Post-Soviet Issues}

$20207(2): 227-236$

6. Кулябина Л., Ногмова А. Динамика сотрудничества России со странами Европы в рамках еврорегионов. Вестник ДА МИД РФ. 2018;4:58

7. Euroregiunile de cooperare transfrontralieră din bazinul inferior al Dunării. Studiu georgrafic / Coord. Radu Săgeată. București. Editura Academiei Române; 2014. C. 30.

8. Legea nr. 151 din 1998 privind dezvoltarea regională în România. URL: http://legislatie. just.ro/Public/DetaliiDocumentAfis/15220 (дата обращения 10.03.2020)

9. Legea nr. 315 din 2004 privind dezvoltarea regională în România. URL: http://legislatie. just.ro/Public/DetaliiDocument/53040 (дата обращения 10.03.2020)

10. Locurile unde se construiește Europa. Adrian Severin în dialog cu Gabriel Andreescu / Adrian Severin. Iași: Polirom; 2000. C.53.

\section{REFERENCES}

1. Romania's development strategy for the next 20 years. Executive summary / Coord.: acad. Ionel-Valentin Vlad. Bucharest: Ed. Romanian Academy; 2017. p. 87 (In Ro.)

2. Kolosov V.N Geography of State Boundaries: Ideas, Achievements, Practice. Institute of Geography, RAS. 2008;5:8 (In Russ.)

3. Introduction to border studies / Coord. S.V. Sevastyanova, Yu. Layne, A.A. Kireeva. Vladivostok: Dalnauka; 2016. p. 45-127 (In Russ.)

4. Classic of geopolitics. XIX century. F.Rattsel, A.Mehen, P.Chaadaev, N.Danilevsky. Moscow: Publishing house «AST»; 2003. 720 p. (In Russ.)

5. Tsygankov P. A. The French geopolitical school in the 2000s: EU relations with Russia. International trends. International trends. 2011;2(26):5 (In Russ.)

6. Kulyabina L.N. Nogmova A.S. Dynamics of Russia's cooperation with European countries in Euroregions. The Herald of the Diplomatic
11. Legea cetățeniei române. URL: http://legislatie. just.ro/Public/DetaliiDocument/121439 (дата обращения 10.03.2020)

12. Iliescu I. Fragmente din viața și istoria trăită. București: Editura Litera; 2011. URL: https:// books.google.ru/books?id=8kWvDwAAQBA $\mathrm{J} \& p g=\mathrm{PT} 1 \& \mathrm{lpg}=\mathrm{PT} 1 \& \mathrm{dq}=$ Fragmente + din $+\mathrm{v}$ ia $\% \mathrm{C} 8 \% 9 \mathrm{Ba}+\% \mathrm{C} 8 \% 99 \mathrm{i}+\mathrm{istoria}+\operatorname{tr} \% \mathrm{C} 4 \% 83 \mathrm{i}$ $\mathrm{t} \% \mathrm{C} 4 \% 83 \&$ source $=$ bl\&ots $=$ ZDLL15S0oE\&si $\mathrm{g}=$ ACfU3U35Tb9nEkGFmjDkqibqbIH5jUnZ 0 w\&hl $=$ ru\&sa $=X \& v e d=2$ ahUKEwjLvpDbhL noAhWq14sKHZJyAHYQ6AEwDXoECBAQ $\mathrm{AQ} \# \mathrm{v}=$ twopage \&q\&f=false (дата обращения 20.03.2020)

13. Scarlat G. Marea neînțelegere cu Bulgaria. De ce să trecem Dunărea. URL: http://fumn. eu/marea-neintelegere-cu-bulgaria-de-ce-satrecem-dunarea/ (дата обращения 17.03.2020)

Academy of the MFA of Russia. 2018;4:58 (In Russ.)

7. Cross-border Euroregions in the Danube basin. Geografical Study / Coord. Radu Sageata. Bucharest: Ed. Romanian Academy; 2014. p. 30 (In Ro.)

8. The Law no. 151 of 1998 on regional development in Romania. URL: http://legislatie.just.ro/ Public/DetaliiDocumentAfis/15220 [Accessed: 10.03.2020] (In Ro.)

9. The Law no. 315 of 2004 on regional development in Romania. URL: http://legislatie.just. ro/Public/DetaliiDocument/53040 [Accessed: 10.03.2020] (In Ro.)

10. Places Where Europe Is Being Constructed: Adrian Severin in Dialogue with Gabriel Andreescu. Iasi: Ed. Polirom; 2000. p. 53 (In Ro.)

11. The Law regarding Romanian citizenship. URL: http://legislatie.just.ro/Public/DetaliiDocument/121439 [Accessed: 10.03.2020] (In Ro.) 


\section{Политические проблемы}

$20207(2): 227-236$

Проблемы постсоветского пространства / Post-Soviet Issues

12. Iliescu I. Fragments of Life and Living History. Bucharest: Ed. Litera; 2011. URL: https://books.google.ru/books?id=8kWvDwAAQBAJ\&pg $=$ PT $1 \& 1 p g=$ PT $1 \& d q=-$ Fragmente+din+via $\% \mathrm{C} 8 \% 9 \mathrm{Ba}+\% \mathrm{C} 8 \% 99 \mathrm{i}+\mathrm{is}-$ toria $+\operatorname{tr} \% \mathrm{C} 4 \% 83$ it $\% \mathrm{C} 4 \% 83 \&$ source $=-$ bl\&ots=ZDLL15S0oE\&sig=ACfU3U35Tb9nEkGFmjDkqibqbIH5jUnZ0w\&hl=ru\&sa $=X$ $\underline{\text { \&ved=2ahUKEwjLvpDbhLnoAhWql- }}$
4sKHZJyAHYQ6AEwDXoECBAQA$\mathrm{Q} \# \mathrm{v}=$ twopage $\& \mathrm{q} \& \mathrm{f}=$ false $\quad$ [Accessed: 20.03.2020] (In Ro.)

13. Scarlat G. The Big Misunderstanding with Bulgaria. Why Not Cross The Danube. URL: http://fumn.eu/marea-neintelegere-cu-bulgaria-de-ce-sa-trecem-dunarea/ [Accessed: 17.03.2020] (In Ro.)

\section{ИНФОРМАЦИЯ ОБ АВТОРЕ / INFORMATION ABOUT THE AUTHOR}

Даниела Г. Драган, Дипломатическая академия МИД России, Москва, Россия; 119992, Россия, Москва, Остоженка, д. 53/2; dragan dana90@yahoo.com
Daniela G. Dragan, Diplomatic Academy of the Ministry of Foreign Affairs of Russia, Moscow, Russia; bld. 53/2, Ostogenka str., Moscow, Russia, 119992;

dragan_dana90@yahoo.com 